IRA-International Journal of Education \&

Multidisciplinary Studies

ISSN 2455-2526; Vol.15, Issue 01 (April, 2019)

Pg. no. 1-15.

Institute of Research Advances

Institute of

http://research-advances.org/index.php/IJEMS

\title{
Managing Youth Unemployment in Developing Economies: An Analysis of Post-Graduate Students' Learning Preferences in Kenya
}

\author{
Francisca Wavinya Ngala ${ }^{1 \#}$ \& Rosemary Wahu Mbogo ${ }^{2}$ \\ 1,2Lecturer, Africa International University, Box 2468600502 , Karen, Nairobi, Kenya. \\ \# corresponding author. \\ Type of Work: Peer Reviewed \\ DOl: http://dx.doi.org/10.21013/jems.v15.n1.p1
}

How to cite this paper:

Ngala, F.W., Mbogo, R.W. (2019). Managing Youth Unemployment in Developing Economies: An Analysis of Post-Graduate Students' Learning Preferences in Kenya. IRA International Journal of Education and Multidisciplinary Studies (ISSN 2455-2526), 15(1), 1-15.doi: http://dx.doi.org/10.21013/jems.v15.n1.p1

(C) Institute of Research Advances.

This work is licensed under a Creative Commons Attribution-Non Commercial 4.0 International License subject to a proper citation to the publication source of the work.

Disclaimer: The scholarly papers as reviewed and published by the Institute of Research Advances (IRA) are the views and opinions of their respective authors and are not the views or opinions of the IRA. The IRA disclaims of any harm or loss caused due to the published content to any party.

Institute of Research Advances is an institutional publisher member of Publishers International Linking Association Inc. (PILA-CrossRef), USA. The institute is an institutional signatory to the Budapest Open Access Initiative, Hungary advocating the open access of scientific and scholarly knowledge. The Institute is a registered content provider under Open Access Initiative Protocol for Metadata Harvesting (OAI-PMH).

The journal is indexed \& included in WorldCat Discovery Service (USA), CrossRef Metadata Search (USA), WorldCat (USA), OCLC (USA), Open J-Gate (India), EZB (Germany) Scilit (Switzerland), Airiti (China), Bielefeld Academic Search Engine (BASE) of Bielefeld University, Germany, PKP Index of Simon Fraser University, Canada. 


\section{ABSTRACT}

It is a common norm to describe education as being fundamental to employment and growth in developing economies. While the highest rate of return is believed to be most experienced in those economies with both skilled and unskilled labour, the greatest responsibility lies with the highly qualified in education as they are most significant in policy formulation. Despite this, youth unemployment has remained a challenge in the 21 st century that most developing countries like Kenya struggle with. This paper entails a study undertaken to explore the management of youth unemployment in Kenya, with a focus on learning preferences of postgraduate students. The study employed a descriptive survey design using the cross-sectional approach to data collection. The population of the study comprised 397 post-graduate students at Africa International University from which a sample size of 199 post-graduate Diploma, Masters' level and Doctoral students were obtained. Questionnaire guide was used for data collection of information on the age and learning preferences of the students. Data analysis was done by descriptive and inferential statistics using regression techniques and presented in tables. A modified version of the Grasha-Riechmann Student Learning Style Scales (GRSLSS) was the learning style inventory that was used to measure student learning preferences. The findings revealed that the majority 161(95.3\%) of post-graduate students were youth and preferred participant, both independent and dependent as well as collaborative learning. The question however is, why has underemployment continued to affect many young Kenyans even with the developing system of education? How can students' learning preferences be a driver to curbing the menace of unemployment?

Keywords: Student learning preferences, Unemployment, Youth, Higher education, Age, Vision 2030.

\section{Introduction}

The International Labour Organization (ILO) [1] described Kenya's economy as being volatile and demonstrating high rates of growth, especially for the last two decades. It is however unfortunate that the positively described development is yet to depict or translate into benefits for the Kenyan youth. According to the ILO report, Kenya had recorded a 5 per cent growth in Gross Domestic Product (GDP) annually but the rate of youth unemployment has shown no to little positive development depicting a 22 per cent unemployment rate in the year 2016 [1]. Unemployment in Kenya has, therefore, become a crucial phenomenon recurring every financial year of the economy's growth. Should Kenya worry about the 'lost generation' as lower youth rates of improving the employment of youth are repeated every year? Is there something that can be done to manage this situation?

Since inception, education has been often considered the key to favourable opportunities in employment. On this, Kenya has progressively improved in recent years despite the lower enrolment rates reported in 2015. A report on Kenya's unemployment situation showed that the rate of enrolment for post-graduate students' enrolments stood at 63,999 (11.9\%) of the universities' student population in total. While the enrolment for $\mathrm{PhD}$ programmes was only $1.3 \%$ of the total university student population, at least 55,461 students had enrolled in Masters Programmes the year in 2015 [2]. Notably, the low rates of postgraduate student enrolments are still disturbing.

One of the goals and aspirations contained in the achievement of Vision 2030 is promoting high achievers to ensure that post-graduate students in the higher learning institutions in Kenya gain quality research and innovation training central to the VISION 2030. How this then can be used to leverage the situation of unemployment of youths in Kenya, is a question that begs to understand.

Several approaches have been employed to overcome the unemployment of youths in Kenya among them involvement of youths in entrepreneurial programmes, funding of such youth entrepreneurship projects and improvement in the education system to train students on hands-on skills which remain a foundational approach. The Organisation for Economic Cooperation and Development (OECD) [3] largely recognises the role that education plays in achieving employment in an economy thus an element that should be embraced by all countries that seek to attain this goal. In support of this, Giuliano and Tsibouris [4] established that the rate of unemployment declines with the increase in the level of education, thus the more individuals receive education, the better their chances of securing a job.

\section{Literature Underpinning}

The unemployment of youth in Kenya has been a crucial concern for policymakers across the country and in all the 47 counties. The number of young people who are not in employment was recorded in a survey by Kenya National 
Bureau of Statistics (KNBS) as 7million with at least 1.4 million being desperate in a job search [5]. This number is alarming and raises a particular concern fearing for a 'lost generation'. These individuals are likely to face long term unemployment challenges with their social disadvantage. This problem has brought along various policy responses from policy makers including educationists to solve [6].

One of the key options by policymakers in promoting education is to improve the education system and the mode of training among the students is done. According to the World Bank Research Programme report (2005-2007) on 'World Development', several factors are pointed out as causing the high rates of unemployment among the youth. Some of the impediments included elements such as organizational policies on employment where work experience for several years is a pre-requisite; lack of practical skills and entrepreneurial skills for school leavers and/or among graduates creating a hurdle to job attainment; and attitude of the students which was also noted a major hindrance to unemployment among the youth [7]. This study therefore with focus on the mode of course delivery to postgraduate students provides a road map to managing unemployment in Kenya with a focus on the education of youth who make up the largest percentage of postgraduate students [8]. Awiti and Scott quote the word of Edmund Burke (1729-1797), "Tell me what are the prevailing sentiments that occupy the minds of your young men, and I will tell you what is to be the character of the next generation" (p.1).

Student learning preferences refer to the specific way through which a student is comfortable to process information. Grasha [9] identifies six learning preferences that are found among learners. He says that some students prefer group or collaborative learning experiences, while others prefer individual or competitive learning experiences. Others prefer discovery or independent learning experiences yet others are more comfortable with a lecture or dependent learning experiences. Still, others are participative and long for a class experience which contrasts sharply with avoidant learners who would not want to participate in class activities at all. All these forms of learning for instance influence the youths' employability in one way or another; for instance, the participative students would have completely different approaches on how they engage in entrepreneurial activities. Learning preference is used synonymously with learning style in this paper.

The study by Bowen [10] which examines the learning styles of African students also forms part of the birth process into this inquiry. Bowen found out that learners from Africa are dependent learners as opposed to those from the West who are independent, a study that was confirmed by Buconyori [11]. The independent learning as compared to dependent learning encourages student participation and engagement which in turn promotes employment. Moleke [12] confirms that a lack of participation in the teaching and learning process heightens the challenge of youth unemployment. A positive attitude towards learning and engaging the young population into education and training can improve the situation and get them closer to the job market. The form of learning style employed by the students is, therefore, a significant mechanism to address the problem of unemployment [12].

However, scholars have argued that;

- Neither vocational learning nor adult learning (postgraduate education) is a promised solution to youth unemployment $[13,14]$. Some of the shortcomings include Employment policy restrictions in which the older and more experienced individuals are favoured in employment than the young. These restrictions, labour markets favouring the older and the less flexible aspect do not provide a platform where the young can transition from school to work through apprenticeships.

- Inadequacy of links on policies between youth education and employment leading to a more difficult response on effective policy development.

- Poor labour market conditions especially the fact that there is a lack of labour demand among employers. The staggering high rates contributing factor on its own [13].

World Youth Report (WYR)[15] recognises the high pressure among youths competing for the global labour market. For instance in Kenya, state employment has been the major single outlet for school graduates containing a strong link between qualifications and occupations. The ever-growing number of school graduates and a high demand for higher education as well as the need for market labour skills necessitates various approaches to the unemployment problem[15]. 
Youth unemployment can also be linked to the higher education institutions with some employers having preferences of graduates from one institution over others due to the confidence that the preferred institutions are perceived to providing high standard quality education [16, 12, 14, 13].In addition, Paul et al. [17]established that most of the employers did not approach the disadvantaged universities for their recruitment initiatives. Furthermore, many of the disadvantaged institutions lack the provision for critical skills such as Engineering courses as the majority are focused on Arts and Humanities subjects, which often are not on demand. Therefore the influence of university education on employment prospects is a major problem that this paper sought to address through an analysis of the learning preferences/ styles of students.

\section{Methodology}

The study was undertaken in Africa International University in which a total of 397 post-graduate students enrolled in three post-graduate levels (Doctoral, Masters and Post-graduate Diploma) programmes were considered. The areas of academic disciplines that the authors considered were Humanities, Social Sciences and Professional and Applied Sciences. These were considered as they form the majority of the unemployed youths in Kenya compared to the science courses. The population entailed both male and female students in their young and middle adulthood ages. Samples of students from all post-graduate programmes at the university were drawn using stratified and systematic random sampling.

Nachmias and Nachmias [18p. 188] and Mugenda and Mugenda [19p. 49] observe that stratified sampling produces more inclusive samples as they incorporate subgroups of small populations which would have been completely left out if other sampling methods were used. Within each stratum, systematic random sampling was done to obtain a random sample. A random sample implies that each person in the target population had an equal chance of being selected. Systematic random sampling was done by first dividing the total population of each programme by the sample sizes obtained for the programmes. A sample size of 50 per cent of the target population was therefore used. Questionnaires were used to collect data.

Age of the respondents formed the independent variable as the study focused on establishing the learning styles used by the students in terms of age which is a determinant to the youth or adult population. The learning preferences were the dependent variables and they included: dependent/independent, avoidant/participant, and competitive/collaborative learning preferences. A 5-point Likert scale with responses ranging from strongly disagree to strongly agree $[20,18]$ was used in the data collection instruments upon which the participants presented their opinions. In three dimensions, the first set of questions investigated the dependent/independent mode of the GRSLSS, the second section was designed to investigate the avoidant/participant dimensions of the GRSLSS and the third was designed to investigate the competitive/collaborative dimensions of the GRSLSS. The benchmarks for deciding the learning preferences of the respondents were set on these three dimensions. Descriptive statistics were used to analyze the data and regression techniques employed for correlation to establish relationships between variables and the magnitude of those relationships.

\section{Results and Discussion}

\section{The Age of the Respondents}

The findings from the questionnaires revealed that majority of the respondents were young adults as they recorded $95.3 \%$ of the population. Young adulthood is a stage in which the majority are defining careers, seeking employment and economic stability. The high percentage could, therefore, be attributed to the large numbers of working-class adults who have enrolled in post-graduate programmes in the university. The respondents who indicated that they were middle age adults recorded only $4.7 \%$, a percentage that was quite low. In middle adulthood, most people are already settled in their careers and this could be attributed to the low percentage of respondents in this category. The late adulthood category was not represented among the participants. Table 1gives a summary of the age of the learners. 
IRA-International Journal of Education $छ$ Multidisciplinary Studies

Table 1. Respondents' age

\begin{tabular}{lllll}
\hline & Frequency & Per cent & \multicolumn{1}{l}{$\begin{array}{l}\text { Valid } \\
\text { Percent }\end{array}$} \\
\hline Valid & 25-35 years & 161 & 95.3 & 95.3 \\
& 36-60 years & 8 & 4.7 & 4.7 \\
& Total & 169 & 100.0 & 100.0 \\
\hline
\end{tabular}

Postgraduate students comprise a large number who are youths being at the age range of 25-35 years. This group of individuals happen to be the largest group of unemployed in Kenya. With the focus of this study being on managing youth unemployment the authors opine that how students opt to receive the message from their lecturers and learning resources determines their ability of employability as discussed hereunder.

\section{Learning Preferences of the Respondents}

This paper through the inquiry from the respondents informs of the learning preferences of post-graduate students at Africa International University. These findings are applicable to other universities of a similar category of students.

The study found that postgraduate students preferred participatory, independent and dependent, as well as collaborative learning preferences.

The study measured students' assertions on specific items in terms of independent /dependent dimensions of the GRSLSS, participant/avoidant dimensions of the GRSLSS and collaborative/competitive dimensions of the GRSLSS. For the purposes of analysis, the five options in the questionnaire were collapsed in three categories of agree, undecided and disagree and the findings of the learning preferences were presented according to the sets of learning preferences as presented by students.

\section{The Independent/dependent Dimensions of the GRSLSS}

The study sought to find out whether the postgraduate students were inclined to independent or dependent learning preferences. They were expected to agree, show no decision or disagree with the twelve assertions. According to the design of the questions, any student who agreed with any of the assertions was regarded as being inclined to independent learning preferences. Any respondent who selected undecided was regarded as not inclined to any of the preferences given and any respondent who disagreed with any assertion was regarded as inclined to dependent learning preferences. The questionnaires that were not filled, or had unclear responses were discarded. The authors were also interested in seeing the relationship between age and learning preferences. Age was considered as it determines the category of an individual whether child, youth or adult. Having established that the majority of the postgraduate students were youth, the study is best fit to explain the unemployment situation despite many young people increasing on their knowledge capacity. Some of the dependent/independent dimensions investigated in this study included:

\section{Feeling very confident about one's ability to learn on their own}

The authors establish the various age categories of postgraduate students and how confident they feel during their learning process. The findings are presented in Table 2.

Table 2. Age and confidence to learn without assistance

\begin{tabular}{|c|c|c|c|c|c|c|c|c|c|}
\hline \multicolumn{2}{|c|}{ Variable } & \multicolumn{2}{|c|}{ Disagree } & \multicolumn{2}{|c|}{ Undecided } & \multicolumn{2}{|c|}{ Agree } & \multicolumn{2}{|c|}{ Total } \\
\hline Age & YA & 48 & $30.7 \%$ & 1 & $0.6 \%$ & 107 & $68.7 \%$ & 156 & $100 \%$ \\
\hline & MA & 1 & $12.5 \%$ & 0 & - & 7 & $87.5 \%$ & 8 & $100 \%$ \\
\hline & Discarded & & & & & & & 5 & \\
\hline Tota & & 49 & & 1 & & 114 & & 169 & \\
\hline
\end{tabular}

The analysis of students' age against confidence in learning showed that the majority of young adults and middleaged adults were likely to prefer independent learning, in relation to confidence in learning. This is because $68.7 \%$ of the young adults and $87.5 \%$ of the middle-aged adults agreed with the assertion that they feel confident about their ability to learn on their own.

The statistical analysis revealed an R-value of .103, which was less than the critical value required to reject a null hypothesis. The corresponding $\mathrm{R}^{2}$ of .011 suggested that $1.1 \%$ of the variance in confidence in learning could be 
accounted for by age, which portrayed quite a weak relationship. The authors, therefore, agree that there is no statistical difference between age and confidence in learning.

\section{Trying to find more about a topic of one's interest}

On dependent and independent learning of the students, the authors examined if the students would try to find out more of a topic if they liked it and findings are as shown in Table 3.

Table 3. Age and finding out more about a topic independently

\begin{tabular}{|c|c|c|c|c|c|c|c|c|}
\hline \multicolumn{2}{|c|}{ Variable } & \multicolumn{2}{|c|}{ Disagree } & Undecided & \multicolumn{2}{|c|}{ Agree } & \multicolumn{2}{|c|}{ Total } \\
\hline Age & YA & 15 & $9.7 \%$ & $2 \quad 1.3 \%$ & 139 & $89 \%$ & 156 & $100 \%$ \\
\hline & MA & 1 & $12.7 \%$ & - & 7 & $87.5 \%$ & 8 & $100 \%$ \\
\hline & Discarded & & & & & & 5 & \\
\hline Total & & 16 & & 2 & 146 & & 169 & \\
\hline
\end{tabular}

Concerning age and finding out more about a topic of interest, Table 3 reports that both young and middle-aged adults were likely to prefer independent learning, by finding out more about a topic. The majority (89\%) of young adults and $87.5 \%$ of middle age adults gave a favourable response to the statement that they find more about a topic on their own. The statistical analysis gave an R-value of .019 , which was smaller than the critical value required to reject a hypothesis of no relationship. An $\mathrm{R}^{2}$ value of .000 suggested that age did not account for the variance in finding more of a topic, which depicts no association. The hypothesis that stated that there was no relationship between age and finding out more about a topic was therefore rejected as the authors affirm that there was no difference, statistically, between both ages and finding out more on a topic.

\section{Interest in developing one's own ideas about course content}

It was also deemed necessary to find out if the postgraduate students like coming up with their own ideas if the course content. The results are as depicted in table 4.

Table 4. Age and developing own ideas about course content

\begin{tabular}{|c|c|c|c|c|c|c|c|c|c|}
\hline \multicolumn{2}{|c|}{ Variable } & \multicolumn{2}{|c|}{ Disagree } & \multicolumn{2}{|c|}{ Undecided } & \multicolumn{2}{|c|}{ Agree } & \multicolumn{2}{|c|}{ Total } \\
\hline Age & YA & 49 & $31.6 \%$ & 12 & $7.7 \%$ & 94 & $60.7 \%$ & 155 & $100 \%$ \\
\hline & MA & 1 & $12.5 \%$ & - & - & 7 & $87.5 \%$ & 8 & $100 \%$ \\
\hline & Discarded & & & & & & & 6 & \\
\hline Tota & & 50 & & 12 & & 101 & & 169 & \\
\hline
\end{tabular}

As reported in Table 4, about age and developing own ideas on course content, it was found out that majority of young and middle-aged adults were likely to prefer independent learning throughthe development of their own ideas about a specific course. This is demonstrated by $60.7 \%$ young adults and $87.5 \%$ middle-aged adults who agreed to the statements. Statistically, the findings revealed an R-value of .136, which was smaller than the critical value required to reject a null hypothesis. An $\mathrm{R}^{2}$ value of .019 suggested that age can explain only $1.9 \%$ of the variance in developing own ideas about course content, which suggests a very negligible relationship. The authors in this regard, did not reject the hypothesis but affirmed that there was no difference, statistically, between age and developing own ideas about the course content.

\section{Not relying on the lecturers to tell students what is important for them to learn}

While it is necessary for students to understand what is important for them in their studies, some could wait to be told on what to do. The study thus sought information on whether the postgraduate students relied on their lecturers to tell them what to learn. The results are shown in Table 5 . 
Table 5. Age and non-reliance on teachers to tell what is important to learn

\begin{tabular}{|c|c|c|c|c|c|c|c|c|c|}
\hline \multicolumn{2}{|c|}{ Variable } & \multicolumn{2}{|c|}{ Disagree } & \multicolumn{2}{|c|}{ Undecided } & \multicolumn{2}{|c|}{ Agree } & \multicolumn{2}{|c|}{ Total } \\
\hline$\overline{\text { Age }}$ & YA & 79 & $50.3 \%$ & 3 & $1.9 \%$ & 75 & $47.8 \%$ & 157 & $100 \%$ \\
\hline & MA & 2 & $25 \%$ & - & - & 6 & $75 \%$ & 8 & $100 \%$ \\
\hline & Discarded & & & & & & & 4 & \\
\hline Total & & 81 & & 3 & & 81 & & 169 & \\
\hline
\end{tabular}

The findings in Table 5 indicate that young adults were likely to prefer dependent learning, with reference to nonreliance on teachers to tell what is important, while the middle-aged adults were likely to prefer independent learning. About half, $50.3 \%$ of the young adults disagreed with the statement that they do not rely on teachers to tell them what is important, while $75 \%$ of the middle-aged adults agreed with the statement. The statistical analysis revealed an R-value of .144, which was smaller than the critical value required to reject the hypothesis of no relationship. An $\mathrm{R}^{2}$ value of .021 suggested that age can explain only $2.1 \%$ of the variance in non-reliance on teachers to tell what is important, which showed a negligible relationship. The authors consequently failed to reject the hypothesis and affirmed that there is no difference, statistically, between both ages and non-reliance on teachers to tell what is important.

\section{Not finding it necessary for lecturer to provide course outlines and notes}

In establishing the form of learning preference in terms of independent and dependent learning, the results in Table 6 were drawn to establish if students found it not necessary for the lecturers to provide course outlines ad notes.

Table 6. Age and non-preference for provision of outlines and notes

\begin{tabular}{|c|c|c|c|c|c|c|c|c|c|}
\hline \multicolumn{2}{|c|}{ Variable } & \multicolumn{2}{|c|}{ Disagree } & \multicolumn{2}{|c|}{ Undecided } & \multicolumn{2}{|c|}{ Agree } & \multicolumn{2}{|c|}{ Total } \\
\hline Age & YA & 148 & $94 \%$ & 1 & $1 \%$ & 8 & $5 \%$ & 157 & $100 \%$ \\
\hline & MA & 6 & $75 \%$ & - & - & 2 & $25 \%$ & 8 & $100 \%$ \\
\hline & Discarded & & & & & & & 4 & \\
\hline Total & & 154 & & 1 & & 10 & & 169 & \\
\hline
\end{tabular}

In relation to age and non-preference for provision of outlines and notes, Table 6, indicates that majority of the young and middle-aged adults were most likely to prefer dependent learning, in relation to non-preference for provision of outlines and notes. Most of them indicated by $94 \%$ and $75 \%$ of the postgraduate students in young adulthood and middle adulthood respectively, disagreed with the statement that they do not like being provided for with outlines and notes. The statistical analysis revealed an R-value of .165 , which was smaller than the critical value required for rejecting the hypothesis of no relationship. The corresponding $\mathrm{R}^{2}$ value of .027 suggested that age can explain only $2.7 \%$ of the variance in non-preference for provision of outlines and notes, which suggests a very negligible relationship. The authors consequently failed to reject the hypothesis and affirmed that there was no difference, statistically, between both ages and non-preference for provision of outlines and notes.

\section{Participant/avoidant dimensions of the GRSLSS}

\section{Classroom sessions typically are worth attending}

In this paper, the authors identified the various forms of student participant and avoidant learning styles. On seeking to know if the students thought that the classes were worth attending, the results in Table 7 were recorded.

Table 7.Age and positive attitude to the attendance of class sessions

\begin{tabular}{llllllllll}
\hline \multicolumn{2}{l}{ Variable } & \multicolumn{2}{l}{ Disagree } & \multicolumn{2}{l}{ Undecided } & \multicolumn{2}{l}{ Agree } & \multicolumn{2}{c}{ Total } \\
\hline Age & YA & 17 & $10.8 \%$ & 1 & $0.6 \%$ & 139 & $88.6 \%$ & 157 & $100 \%$ \\
& MA & 1 & $12.5 \%$ & - & - & 7 & $87.5 \%$ & 8 & $100 \%$ \\
& Discarded & & & & & & & 4 & \\
Total & & 18 & & 1 & & 146 & \multicolumn{2}{c}{169} \\
\hline $\mathrm{R}=.086$ & $\mathrm{R}^{2}=.007$ & critical value $=.950$ & $\mathrm{df}=2$ & \multicolumn{2}{l}{ Confidence level $=0.05$}
\end{tabular}


From Table 7, which relates age to positive attitude to attendance of class sessions, it was found out that majority of both young and middle-aged adults were likely to prefer participant learning, in relation to a positive attitude to class attendance. Most, $88.6 \%$ and $87.5 \%$ of young and middles age adults respectively agreed with the assertion that class sessions are worth attending. Statistical analysis revealed an R-value of .086, which was smaller than the critical value required to reject the hypothesis of no relationship. An $\mathrm{R}^{2}$ value of .007 suggested that age can explain only $0.7 \%$ of the variance in a positive attitude to the attendance of class sessions, which suggests a very negligible relationship. Agreeably, the authors failed to reject the hypothesis and affirmed that there was no difference, statistically, between both ages and positive attitude to the attendance of class sessions.

\section{Studying for tests with other students}

Participatory or avoidant learning is also seen in the aspect of students being able to study for exams or test with others. The findings in table 8 indicate the students' responses.

Table 8. Age and preference to study for tests with other students

\begin{tabular}{|c|c|c|c|c|c|c|c|c|}
\hline \multicolumn{2}{|c|}{ Variable } & \multicolumn{2}{|c|}{ Disagree } & Undecided & \multicolumn{2}{|c|}{ Agree } & \multicolumn{2}{|c|}{ Total } \\
\hline Age & $\mathrm{YA}$ & 37 & $24 \%$ & $5 \quad 3.2 \%$ & 112 & $72.8 \%$ & 154 & $100 \%$ \\
\hline & MA & 5 & $62.5 \%$ & - & 3 & $35.5 \%$ & 8 & $100 \%$ \\
\hline & Discarded & & & & & & 7 & \\
\hline Total & & 42 & & 5 & 115 & & 169 & \\
\hline
\end{tabular}

Table 8 in relation to age and studying for tests with other students, shows that majority of young adults were likely to prefer participant learning, with reference to studying for tests with other students, as $72.8 \%$ responded favourably to the statement that they like to study for tests with other students. The middle-aged adults were likely to prefer avoidant learning, with reference to studying for tests with other students, as $62.5 \%$ responded unfavourably to the assertion. The analysis statistically revealed an R-value of .177, which was smaller than the critical value required for rejecting the hypothesis of no relationship. An $\mathrm{R}^{2}$ value of .031 suggested that age can account for only $3.1 \%$ of the variance in preference to study for tests with other students, which suggests a very negligible relationship. The hypothesis was therefore not rejected with an affirmation that there was no difference, statistically, between both ages and studying for tests with other students.

3. Students not liking to be ignored by teachers in class

Another aspect of the participatory/avoidance learning style of postgraduate students was established as shown in Table 9.

Table 9. Age and non-preference for being ignored by teachers in class

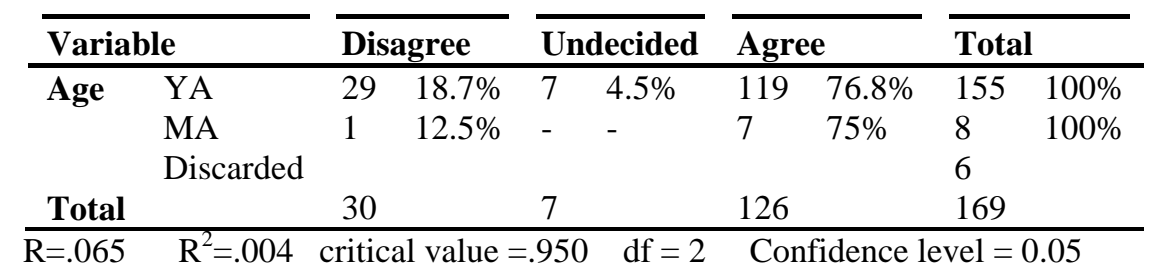

According to Table 9, which relates age and non-preference for being ignored by teachers in class, majority of young and middle-aged adults were likely to prefer participant learning, with reference to non-preference for being ignored by teachers in class. $76.8 \%$ and $75 \%$ of young adults and middle-aged adults respectively gave a favourable response to the assertion that they did not like being ignored by teachers in class. The statistical analysis revealed an R-value of .065 , which was smaller than the critical value required for rejecting the hypothesis of no relationship. An $\mathrm{R}^{2}$ value of .004 suggested that age can explain only $0.4 \%$ of the variance in non-preference for being ignored by teachers in class, which suggests a very negligible relationship. The authors consequently failed to reject the hypothesis and affirmed that there was no difference, statistically, between both ages and non-preference for being ignored by teachers in class. 
4. Excitement about materials covered in class

On class attendance as a form of students learning preferences, the authors sought to establish by age if the postgraduate students were excited about the materials covered in class. The findings are as presented in Table 10.

Table 10. Age and excitement by the material covered in class

\begin{tabular}{|c|c|c|c|c|c|c|c|c|}
\hline \multicolumn{2}{|c|}{ Variable } & \multicolumn{2}{|c|}{ Disagree } & Undecided & \multicolumn{2}{|c|}{ Agree } & \multicolumn{2}{|c|}{ Total } \\
\hline \multirow[t]{3}{*}{ Age } & YA & 16 & $10.1 \%$ & $3.2 \%$ & 136 & $86.7 \%$ & 157 & $100 \%$ \\
\hline & MA & 1 & $12.5 \%$ & - & 7 & $87.5 \%$ & 8 & $100 \%$ \\
\hline & Discarded & & & & & & 4 & \\
\hline Tota & & 17 & & 5 & 143 & & 169 & \\
\hline
\end{tabular}

As reported in Table 10, the analysis on age in relation to the excitement by the material covered in class, revealed that there were no major differences in learning preferences between young and middle-aged adults. Majority of them agreed with the assertion that they are usually excited about material covered in class, at the rate of $86.7 \%$ and $87.5 \%$ of the young and middle-aged adults, respectively which suggested likely preference for participant learning, with reference to the excitement by the material covered in class. Statistically, the analysis revealed an R-value of .082 , which was smaller than the critical value required to reject the hypothesis of no relationship. An $\mathrm{R}^{2}$ value of .003 suggested that age can explain only $0.3 \%$ of the variance in the excitement by the material covered in class, which suggests a very negligible relationship. It was based on this that the authors failed to reject the hypothesis and affirmed that there was no difference, statistically, between both ages and excitement by the material covered in class.

5. Paying attention during class sessions

In addition to the participatory/avoidance dimensions to student learning, the authors sought to establish if the postgraduate students found it difficult to pay attention during class sessions. The results of the study are shown in Table 11.

Table 11.Age and not finding it difficult to pay attention

\begin{tabular}{|c|c|c|c|c|c|c|c|c|}
\hline \multicolumn{2}{|c|}{ Variable } & \multicolumn{2}{|c|}{ Disagree } & Undecided & \multicolumn{2}{|c|}{ Agree } & \multicolumn{2}{|c|}{ Total } \\
\hline Age & YA & 16 & $10.2 \%$ & $5 \quad 3.2 \%$ & 136 & $86.6 \%$ & 157 & $100 \%$ \\
\hline & MA & 1 & $12.5 \%$ & - & 7 & $87.5 \%$ & 8 & $100 \%$ \\
\hline & Discarded & & & & & & 4 & \\
\hline Tota & & 17 & & 5 & 143 & & 169 & \\
\hline
\end{tabular}

From the findings of the study as shown in Table 11 in relation to the age factor and students learning preference in terms of finding it difficult to pay attention in class sessions, majority of the young and middle-aged adults were likely to prefer participant learning, with reference to not finding it difficult to pay attention. This was suggested by $86.6 \%$ and $87.5 \%$ of young and middle-aged adults, respectively who affirmed the assertion that they did not find it difficult to pay attention in class. The statistical analysis revealed an R-value of .017, which was smaller than the critical value required for rejecting the hypothesis of no relationship. An $\mathrm{R}^{2}$ value of .000 suggested that age did not account for the variance in not finding it difficult to pay attention, which suggests no relationship. The authors, therefore, failed to reject the hypothesis and affirmed that there was no difference, statistically, between both ages and not finding it difficult to pay attention.

6. Students day-dreaming in class

Table 12 is a presentation of the study findings that sought to establish if the students day dreamt in class during the lessons. 
Table 12. Age and not day-dreaming in class

\begin{tabular}{|c|c|c|c|c|c|c|c|c|c|}
\hline \multicolumn{2}{|c|}{ Variable } & \multicolumn{2}{|c|}{ Disagree } & \multicolumn{2}{|c|}{ Undecided } & \multicolumn{2}{|c|}{ Agree } & \multicolumn{2}{|c|}{ Total } \\
\hline Age & YA & 54 & $34.6 \%$ & 10 & $6.4 \%$ & 92 & $58.9 \%$ & 156 & $100 \%$ \\
\hline & MA & 1 & $12.5 \%$ & - & - & 7 & $87.5 \%$ & 8 & $100 \%$ \\
\hline & Discarded & & & & & & & 4 & \\
\hline Tota & & 55 & & 10 & & 99 & & 169 & \\
\hline
\end{tabular}

According to the findings on Table 12, which relates age and not day-dreaming in class, it was found that majority of the young adults and middle-aged adults were likely to prefer participant learning, in relation to not day-dreaming in class. $58.9 \%$ of young adults and $87.5 \%$ of middle-aged adults affirmed the statement that they rarely day-dream in class. The statistical analysis revealed an R-value of .161, which was less than the critical value required to reject the hypothesis of no relationship. An $\mathrm{R}^{2}$ value of .026 suggested that age can explain only $2.6 \%$ of the variance in not day-dreaming in class, which suggests a very negligible relationship. The authors, therefore, failed to reject the hypothesis and affirmed that there was no difference, statistically, between both ages and not day-dreaming in class.7. Non-boredom classroom activities

Table 12.Age and non-boredom with class activities

\begin{tabular}{|c|c|c|c|c|c|c|c|c|c|}
\hline \multicolumn{2}{|c|}{ Variable } & \multicolumn{2}{|c|}{ Disagree } & \multicolumn{2}{|c|}{ Undecided } & \multicolumn{2}{|c|}{ Agree } & \multicolumn{2}{|c|}{ Total } \\
\hline Age & YA & 51 & $33 \%$ & 12 & $7.7 \%$ & 92 & $59.3 \%$ & 155 & $100 \%$ \\
\hline & MA & 4 & $50 \%$ & - & - & 4 & $50 \%$ & 8 & $100 \%$ \\
\hline & Discarded & & & & & & & 6 & \\
\hline Total & & 55 & & 12 & & 96 & & 169 & \\
\hline
\end{tabular}

An analysis on age in relation to non-boredom with class activities, as shown in Table 12, revealed that majority of young adults were likely to prefer participant learning, with reference to non-boredom with class activities, as shown by $59.3 \%$ agreement with the assertion that classroom activities are never boring. The statistical analysis revealed an R-value of .018, which was smaller than the critical value required for the rejection of the hypothesis of no relationship. The corresponding $\mathrm{R}^{2}$ value of .000 suggested that age did not explain any percentage of the variance in non-boredom with class activities, which suggests no relationship. The authors, as a result, failed to reject the hypothesis and affirmed that there was no difference, statistically, between both ages and non-boredom with class activities.

\section{Collaborative/Competitive Dimensions of the GRSLSS}

1. Sharing of ideas among students

This study also analyzed the collaborative aspect vs the competitive nature of students. Among the aspect, the authors sought if they thought students should be encouraged to share ideas with each other. The findings are as shown in Table 13.

Table13. Age and sharing ideas with each other

\begin{tabular}{|c|c|c|c|c|c|c|c|c|c|}
\hline \multicolumn{2}{|c|}{ Variable } & \multicolumn{2}{|c|}{ Disagree } & \multicolumn{2}{|c|}{ Undecided } & \multicolumn{2}{|c|}{ Agree } & \multicolumn{2}{|c|}{ Total } \\
\hline Age & YA & 7 & $4.5 \%$ & - & - & 148 & $95.5 \%$ & 155 & $100 \%$ \\
\hline & MA & 1 & $12.5 \%$ & - & - & 7 & $87.5 \%$ & 8 & $100 \%$ \\
\hline & Discarded & & & & & & & 6 & \\
\hline Total & & 8 & & & & 155 & & 169 & \\
\hline
\end{tabular}


When the age of the respondents was analyzed in relation to sharing ideas with each other, as indicated in Table 13, it was revealed that majority of the young and middle-aged adults were likely to prefer collaborative learning, with reference to sharing ideas with each other. $95.5 \%$ and $87.5 \%$ of young and middle-aged adults respectively, affirmed the statement that students should be encouraged to share their ideas with each other. The statistical analysis revealed an R-value of .100, which was smaller than the critical value required for the rejection of the hypothesis of no relationship. The corresponding $\mathrm{R}^{2}$ value of .010 suggested that age can explain only $1 \%$ of the variance in sharing ideas with each other, which suggests a very negligible relationship. The authors consequently failed to reject the hypothesis and affirmed that there was no difference, statistically, between both age groups and sharing ideas with each other.

\section{Students enjoying to work with other students on class activities}

As portrayed in Table 14, the study sought to establish if the postgraduate students enjoyed working with others on class activities.

Table 14. Age and enjoyment in working with other students

\begin{tabular}{|c|c|c|c|c|c|c|c|c|c|}
\hline \multicolumn{2}{|c|}{ Variable } & \multicolumn{2}{|c|}{ Disagree } & \multicolumn{2}{|c|}{ Undecided } & \multicolumn{2}{|c|}{ Agree } & \multicolumn{2}{|c|}{ Total } \\
\hline Age & YA & 17 & $11.1 \%$ & 1 & $0.7 \%$ & 135 & $88.2 \%$ & 153 & $100 \%$ \\
\hline & MA & 2 & $25 \%$ & - & - & 6 & $75 \%$ & 8 & $100 \%$ \\
\hline & Discarded & & & & & & & 8 & \\
\hline Tota & & 19 & & 1 & & 141 & & 169 & \\
\hline
\end{tabular}

When age was analyzed in relation to enjoyment in working with other students, as shown in Table 14, it was found out that the majority of young and middle-aged adults were likely to prefer collaborative learning, with reference to enjoyment in working with other students. $88.2 \%$ and $75 \%$ of young and middle-aged adults, respectively affirmed assertion that they enjoyed working with other students on class activities. Statistically, the analysis revealed an Rvalue of .095 , which was smaller than the critical value required for the rejection of the hypothesis of no relationship. An $\mathrm{R}^{2}$ value of .009 suggested that age can explain only $0.9 \%$ of the variance in enjoyment in working with other students, which suggests a very negligible relationship. The authors, therefore, failed to reject the hypothesis and affirmed that there was no difference, statistically, between both age groups and enjoyment in working with other students.

\section{Being one of the best students is not important to me}

Another aspect that would identify if students preferred competitive or collaborative mode of learning was to establish if they were concerned about being the best student. The study results are as sown in Table 15.

Table15. Age and non-importance of being the best student

\begin{tabular}{|c|c|c|c|c|c|c|c|c|c|}
\hline \multicolumn{2}{|c|}{ Variable } & \multicolumn{2}{|c|}{ Disagree } & \multicolumn{2}{|c|}{ Undecided } & \multicolumn{2}{|c|}{ Agree } & \multicolumn{2}{|c|}{ Total } \\
\hline Age & YA & 76 & $48.7 \%$ & 1 & $0.6 \%$ & 79 & $50.6 \%$ & 156 & $100 \%$ \\
\hline & MA & 2 & $25 \%$ & - & - & 6 & $75 \%$ & 8 & $100 \%$ \\
\hline & Discarded & & & & & & & 5 & \\
\hline Total & & 79 & & 1 & & 85 & & 169 & \\
\hline
\end{tabular}

Analysis on age and non-importance of being one of the best students, according to Table 38a, revealed that the majority of the middle-aged adults were likely to prefer collaborative learning, in relation to non-importance of being one of the best students. $75 \%$ of middle-aged adults affirmed the assertion that it was not important to be one of the best students. The young adults were likely to prefer collaborative learning in relation to non-importance of being one of the best students, as they were represented by $50.7 \%$ of those who agreed with the assertion. The statistical analysis revealed an R-value of .138, which was smaller than the critical value required for the rejection of the hypothesis of no relationship. An $\mathrm{R}^{2}$ value of .019 suggested that age can explain only $1.9 \%$ of the variance in non-importance of being the best students, which suggests a very negligible relationship. The authors consequently failed to reject the hypothesis and affirmed that there was no difference, statistically, between both age groups and non-importance of being one of the best students. 
5. Being recognized by the lecturer for good work done

The study also sought to find out if the postgraduate students liked receiving recognition good work as shown in Table 16.

Table 16. Age and dislike for teacher recognition

\begin{tabular}{|c|c|c|c|c|c|c|c|c|c|}
\hline \multicolumn{2}{|c|}{ Variable } & \multicolumn{2}{|c|}{ Disagree } & \multicolumn{2}{|c|}{ Undecided } & \multicolumn{2}{|c|}{ Agree } & \multicolumn{2}{|c|}{ Total } \\
\hline Age & YA & 101 & $64.7 \%$ & 9 & $5.8 \%$ & 46 & $29.5 \%$ & 156 & $100 \%$ \\
\hline & MA & 5 & $71.4 \%$ & - & - & 2 & $28.6 \%$ & 7 & $100 \%$ \\
\hline & Discarded & & & & & & & 6 & \\
\hline Total & & 106 & & 9 & & 48 & & 169 & \\
\hline
\end{tabular}

With regard to age and dislike for teacher recognition, Table 16 shows that the majority of both young and middleaged adults were likely to prefer competitive learning, with reference to dislike for teacher recognition. $64.7 \%$ of young adults and $71.4 \%$ of middle-aged adults responded unfavourably to the assertion that they disliked teacher recognition. The statistical analysis revealed an $\mathrm{R}$-value of .027 , which was smaller than the critical value required to reject the hypothesis of no relationship. The corresponding $\mathrm{R}^{2}$ value of .001 suggested that age can explain only $0.1 \%$ of the variance in dislike for teacher recognition, which suggests a very negligible relationship. The authors consequently failed to reject the hypothesis and affirmed that there was no difference, statistically, between both ages and dislike for teacher recognition.

\section{Students finding it not necessary to compete with other students in the class}

The results presented in Table 17 are findings on the aspect of whether the postgraduate students considered competition necessary for passing across ideas.

Table 17. Age and not competing to get ideas across

\begin{tabular}{lllllllll}
\hline Variable & Disagree & \multicolumn{2}{c}{ Undecided } & Agree & \multicolumn{3}{c}{ Total } \\
\hline Age & 46 & $29.5 \%$ & 2 & $1.3 \%$ & 108 & $69.2 \%$ & 156 & $100 \%$ \\
YA & 1 & $12.5 \%$ & - & - & 7 & $87.5 \%$ & 8 & $100 \%$ \\
MA & & & & & & & 5 & \\
$\begin{array}{l}\text { Discarde } \\
\text { d }\end{array}$ & & & & & & & & \\
Total & 47 & & 2 & & 115 & & 165 & \\
\hline $\mathrm{R}=.114$ & $\mathrm{R}^{2}=.013$ & critical value $=.950$ & $\mathrm{df}=2$ & Confidence level $=0.05$ & &
\end{tabular}

Analysis on age in relation to not competing to get ideas across, as reported in Table 17, revealed that the majority of both young and middle-aged adults were likely to prefer collaborative learning, with reference to not competing to get ideas across. $69.2 \%$ of young adults and 87.5 middle-aged adults affirmed the statement that they did not find it necessary to compete to get ideas across. The statistical analysis revealed an R-value of .114, which was smaller than the critical value required for rejecting the hypothesis of no relationship. An $\mathrm{R}^{2}$ value of .013 suggested that age can explain only $1.3 \%$ of the variance in not competing to get ideas across, which suggests a very negligible relationship. The authors consequently failed to reject the hypothesis and affirmed that there was no difference, statistically, between both age groups and not competing to get ideas across.

7. Students do not have to be aggressive to do well in courses

It was also deemed important to find out the attitude of students on aggressiveness in-class work. The findings presented in Table 18 indicate their responses. 
IRA-International Joumal of Education $\Xi^{\circ}$ Multidisciplinary Studies

Table 18. Age and non-aggression to do well in courses

\begin{tabular}{lllllllll}
\hline $\begin{array}{l}\text { Variabl } \\
\text { e }\end{array}$ & Disagree & & \multicolumn{2}{l}{ Undecided } & Agree & \multicolumn{2}{l}{ Total } \\
\hline Age & 73 & $46.8 \%$ & 6 & $3.8 \%$ & 77 & $49.4 \%$ & 156 & $100 \%$ \\
YA & 2 & $40 \%$ & - & - & 3 & $60 \%$ & 5 & $100 \%$ \\
$\begin{array}{l}\text { MA } \\
\begin{array}{l}\text { Discard } \\
\text { ed }\end{array}\end{array}$ & & & & & & & 8 & \\
Total & 75 & & 6 & & 79 & & 169 & \\
\hline $\mathrm{R}=.025$ & $\mathrm{R}^{2}=.001$ & critical value $=.950$ & $\mathrm{df}=2$ & Confidence level $=0.05$ &
\end{tabular}

Analysis of age in relation to non-aggression to do well in courses, as reported in Table 18, revealed that the majority of middle-aged and young adults were likely to prefer collaborative learning, with reference to nonaggression. This is demonstrated by $60 \%$ of middle-aged adults and $49.4 \%$ of young adults who responded favourably to the statement that students do not have to be aggressive to well in courses. The statistical analysis revealed an R-value of .025 , which was smaller than the critical value required to reject the hypothesis of no relationship. The corresponding $\mathrm{R}^{2}$ value of .001 suggested that age can explain only $0.1 \%$ of the variance in nonaggression to do well in courses, which suggests a very negligible relationship. The authors consequently failed to reject the hypothesis and affirmed that there was no difference, statistically, between both age groups and nonaggression to do well in courses.

9.Students' interest in leading a group

The study also sought to establish if students liked being leaders of groups during class activities and the results in Table 19 were established.

Table 19. Age and not leading a group

\begin{tabular}{lllllllll}
\hline Variabl & Disagree & \multicolumn{3}{l}{ Undecided } & Agree & & Total \\
e & & & & & & & \\
\hline Age YA & 74 & $47.4 \%$ & 17 & $10.9 \%$ & 65 & $41.7 \%$ & 156 & $100 \%$ \\
MA & 4 & $50 \%$ & 1 & $12.5 \%$ & 3 & $37.5 \%$ & 8 & $100 \%$ \\
$\begin{array}{l}\text { Discard } \\
\text { ed }\end{array}$ & & & & & & & 5 & \\
$\begin{array}{l}\text { Total } \\
\mathrm{R}=.063\end{array}$ & 78 & $\mathrm{R}^{2}=.004$ & critical value $=.950$ & $\mathrm{df}=2$ & Confidence level $=0.05$ & & & \\
\end{tabular}

With regard to age and desire for leadership, Table 19 reports that the majority of middle-aged adults were likely to prefer competitive learning, with reference to the desire for group leadership. Half, (50\%) of middle-aged adults disagreed with the assertion that they did not like being a leader of a group. The statistical analysis revealed an Rvalue of .063 , which was smaller than the critical value required for rejection of the null hypothesis. An $\mathrm{R}^{2}$ value of .004 suggested that age can explain only $0.4 \%$ of the variance in not leading a group, which suggests a very negligible relationship. The authors consequently failed to reject the hypothesis and affirmed that there was no difference, statistically, between both age groups and desire for group leadership.

\section{Conclusion}

This paper has covered a range of learning preferences/ styles in relation to postgraduate students' age. The three forms of learning styles identified are dependent/independent, avoidant/participant, and competitive/collaborative dimensions. In all the dimensions of learning, the authors have been particular about each item inquiring on which method was most preferred by students. While the middle-aged portrayed a high level of independent learning, the young adults who makeup the majority of the postgraduate students and are the youths in the economy preferred dependent learning. On the other hand, both ages had an inclined preference for collaborative than competitive learning an aspect that is experienced in the institutions of higher learning. Could a competitive attitude drive more youths towards the path of the labour market than the collaborative nature? None the less, most of the postgraduate 
students considered a more participatory way of learning as compared to the avoidant mode. In this, we conclude that the mode of learning preferences largely influences the level of students' employability in the job market. Hence there is a need to help the youths understand the best methods to become vibrant in the economy towards the achievement of vision 2030 .

\section{Recommendations}

The authors make recommendations in this paper on how to make learning effective in education training by focusing on the students' learning preferences. Therefore to enhance youth employability in the country, there is an urgent need to:

1. Institute a transition system that is stronger linking educational training and work; this could be with a concentration on vocational education and training infrastructures. Enhancing work quality for youths through vocational training, employer skill-based learning and apprenticeships.

2. Have the government's focus on policies on job generation and progressive job opportunities to improve the state of employability

3. Engage social partners and employers in initiating learning opportunities for youth through reflection on the skills need and the job market.

4. Establish new and innovative approaches by embracing learning as the initial step towards employment.

However, while such actions may come with some challenges and become difficult to implement, policy developments that guarantee youth employment should be put in place to enable opportunities to move in the proposed direction. This all aimed at ensuring postgraduate education plays the part in tackling youth unemployment across Kenya and other developing economies.

\section{References}

[1]. ILO. (2016). World employment and social outlook 2016: Trends for youth. Geneva: International Labour Organization.

[2]. Danner, H. Kerretts-Makau, M., \& Nebe, J.M. (2016) (Eds.). Youth unemployment in Kenya: A ticking time bomb. Nairobi: Longhorn Publishers.

[3]. OECD. (2008). Education at a glance: OECD indicators. Paris: Organisation for Economic Cooperation and Development.

[4]. Giuliano, P., \& Tsibouris, G. (2001).Unemployment characteristics and persistence in South Africa. Washington DC: IMF.

[5]. KNBS. (2018). Kenya's unemployment rate. Nairobi: KNBS

[6]. Manpower Group (2018). Solving the talent shortage. 2018 Talent Shortage Survey

[7]. World Bank. 2008. Youth and employment in Africa: The potential, the problem, the promise (English). Africa development indicators. Washington, DC: World Bank Group.

[8]. Awiti, A. O. \& Scott, B. (2016).The Kenya youth survey report. The Agakhan University.

[9]. Grasha, A. F. (1996). Teaching with style a practical guide to enhancing learning by understanding teaching and learning styles. Pittsburgh: PA Alliance.

[10]. Bowen, D. N. (1984).Cognitive Styles of African theological students and the implications of these styles for bibliographic instruction. PhD Dissertation. Florida State University.

[11]. Buconyori, E. (1991). Cognitive styles and the development of reasoning among younger African students in Christian higher education. (PhD Dissertation).Trinity Evangelical Divinity School. Deerfield, Illinois: U.M.I.Dissertation). Florida State University

[12]. Moleke, P. (2012). Young South Africans in the labour market: Obstacles they face when entering the labour market and options for inclusion. Presentation at Economic Justice for the Next Generation Conference, Johannesburg, 27 July 2012.

[13]. Oluwajodu, F., Blaauw, D., Greyling, L., \& Kleynhans, E. (2015). Graduate unemployment in South Africa: Perspectives from the banking sector. SA Journal of Human Resource Management,13(1), 1-9.

[14]. Mendolia, S., \&Walker, I.(2015). Youth unemployment and personality traits. doi: 10.1186/s40172-015-0035-3

[15]. World Youth Report (2005).Young people today, and in 2015.United Nations

[16]. Baldry, K. (2013). Graduate unemployment in South Africa: prevalence, characteristics and perceived causes. (MA dissertation), University of the Witwatersrand, Johannesburg, South Africa.

[17]. Pauw, K., Oosthuizen, M., \& Van Der Westhuizen, C. (2008). Graduate unemployment in the face of skills shortage: A labour market paradox, South African Journal of Economics 76(1), 45-57. 
[18]. Nachmias, C. F., \& Nachmias, D. (1996).Research methods in the social sciences, (5 $5^{\text {th }}$ d). New York: St. Martin's Press.

[19]. Mugenda, M.O., \& Mugenda, A. (2003). Research methods: Qualitative and quantitative Approaches. Nairobi: Africa Center for technology studies.

[20]. Gall, M., Gall, J. P., \& Borg, W.R. (2003). Educational research: An introduction. Boston: Pearson. 